\title{
RUMINATIVE RESPONSE STYLES AND DELAY OF SEEKING DIAGNOSIS FOR BREAST CANCER SYMPTOMS
}

\author{
SONJA LYUBOMIRSKY, FAZILET KASRI, OLIVIA CHANG, \\ AND IRENE CHUNG \\ University of California, Riverside
}

\begin{abstract}
Women with a ruminative style-a tendency to focus repetitively on the meaning, causes, and consequences of their distress-were hypothesized to delay seeking a diagnosis from a healthcare professional for a potentially dangerous breast symptom relative to women without a ruminative style. In Study 1, 147 female "ruminators" and "non-ruminators" read a vignette in which they imagined they had just discovered a change in their breast, completed measures of affect, and reported their intentions to seek care for this breast symptom. Ruminators were significantly less likely to intend to call the doctor immediately after finding an imaginary breast lump than were non-ruminators. In Study 2, 70 women breast cancer survivors recalled the dates related to their symptom finding and their affective responses to symptom finding. Ruminators delayed the presentation of their breast cancer symptoms to a healthcare professional 39 days longer than did non-ruminators. Furthermore, in both studies, the effects of ruminative style on delay appeared to be moderated in part by the experience of positive mood at the time of symptom discovery. The results of these two studies have significant applied implications, suggesting that ruminative response styles play a role in the delay of presentation of health symptoms.
\end{abstract}

Sonja Lyubomirsky, Fazilet Kasri, Olivia Chang, and Irene Chung, Department of Psychology, University of California, Riverside. Fazilet Kasri is now at the Los Angeles County Office of Education, and Olivia Chang is at the Department of Psychology, University of Kansas.

This research was supported in part by a B-START grant from the National Institutes of Mental Health, a Cancer Research Coordinating Committee grant from the University of California, and the President's Undergraduate Fellowship from the University of California. We are grateful to Robert Rosenthal and Robin DiMatteo for incisive feedback about this research.

Address correspondence to Sonja Lyubomirsky, Department of Psychology, University of California, Riverside, CA 92521; E-mail: sonja@citrus.ucr.edu. 
Breast cancer is the most commonly diagnosed cancer in the United States, after skin cancer, and one of the leading causes of cancer death among American women (National Cancer Institute, 2003). Although breast cancer death rates have decreased over the years, the incidence of breast cancer has increased from 1 in 20 women in 1960 to 1 in 8 women today (National Breast Cancer Foundation, 2004). Many studies have shown that the earlier a woman seeks help after discovering a breast symptom, the less advanced her symptoms will be (Levy, 1983; Neave, Mason, \& Kay, 1990; Richardson, Langholz, Bernstein, Burciaga, Danley, \& Ross, 1992; Wilkinson et al., 1979), and thus the higher likelihood of her survival (Funch, 1984; Levy, 1983; Richards, Smith, Ramirez, Fentiman, \& Rubens, 1999; Rossi et al., 1990; Wilkinson et al., 1979). Yet, it has been estimated that approximately one-third of women with confirmed breast cancer originally delayed seeking a diagnosis for at least three months or longer after finding their first symptom (Facione, Miaskowski, Dodd, \& Paul, 2002). Given that 65 to $85 \%$ of breast cancer cases appear to be initiated with a self-discovered lump (Facione, 1993), delay is an important psychological factor to examine with respect to breast cancer because of its link to decreased survival (Elwood \& Moorehead, 1980; Funch, 1984; Machiavelli et al., 1989; for a review, see Facione, 1993). Consequently, the last two decades of cancer research have witnessed increased interest in what factors influence delay, usually operationalizing delay as the period between the first discovery of a breast symptom and the presentation of the symptom to a healthcare professional.

\section{EMOTIONAL RESPONSES AND DELAY}

A growing body of research is showing that emotional responses related to the discovery of symptoms (e.g., such as those that occur during breast self-examinations) are associated with delay of diagnosis seeking (Ajekigbe, 1991; MacFarlane \& Sony, 1992; Mor, Guadagnoli, \& Wool, 1987). In her review of the research literature, Facione (1993) discussed a variety of emotional responses related to symptom finding and presented a list of the different fears women tend to experience after the discovery of their symptoms, such as fear of death, fear of doctors and hospitals, fear of embarrassment, fear of disfigurement, and fear of chemotherapy. In one study, the experience of some of these fears-in particular, fear of dying, fear of breast loss, and fear of cancer itself-were associated with delay (Magarey, Todd, \& Blizard, 1977; see also De Nooijer, Lechner, \& De Vries, 2001; Grunfeld, Hunter, Ramirez, \& Richards, 2003). This finding suggests that intense negative emotions may 
prevent women from taking appropriate action in regard to their breast symptoms. Little is known about the role of positive emotions, however.

Although such studies have significantly advanced our knowledge of the role of emotional factors in delay, research on delay in general has suffered a lack of theoretical direction and theoretical application. The few exceptions to this trend are theoretical models of illness behavior that contribute to our understanding of the cognition of "delayers" (Andersen \& Cacioppo, 1990, 1995; Leventhal, 1970; Leventhal \& Diefenbach, 1991). Even these models, however, do not directly address the mechanisms underlying delay or consider possible individual differences in delay. The studies described here aim to expand this research by drawing on a social cognitive theory that delineates differences in individual styles of responding to negative emotions - that is, ruminative response styles theory (Lyubomirsky \& Tkach, 2004; Nolen-Hoeksema, 1991). This theory is proposed to elucidate why women delay, as well as to provide a cognitive perspective to the understanding of delay processes.

\section{RUMINATIVE RESPONSE STYLES THEORY}

A ruminative response style involves a tendency to focus repetitively on the meanings, causes, and consequences of one's distress (Nolen-Hoeksema, 1991, 2003). Self-focused rumination in the presence of a negative or depressed mood has been posited to lead to vicious cycles between mood, thinking, and problem solving, and, as a result, to further enhance distress (Nolen-Hoeksema, 1991; see Lyubomirsky \& Tkach, 2004, for a review). Ruminative response styles may exacerbate and prolong distress, first, by fostering negatively biased thinking - that is, by triggering negative memories (Lyubomirsky, Caldwell, \& Nolen-Hoeksema, 1998), negative self-evaluations (Lyubomirsky, Tucker, Caldwell, \& Berg, 1999), and pessimistic inferences, attributions, and predictions (Lyubomirsky \& Nolen-Hoeksema, 1995). Second, ruminative responses may interfere with instrumental behaviors and attention-for example, by impairing concentration on academic tasks (Lyubomirsky, Kasri, \& Zehm, 2003) and reducing confidence and commitment to one's own plans to resolve a novel problem (Ward, Lyubomirsky, Sousa, \& Nolen-Hoeksema, 2003). Third, because of these adverse effects on thinking and concentration, ruminative response styles may interfere with more complex and interpersonal problem solving (Lyubomirsky et al., 1999; Lyubomirsky \& Nolen-Hoeksema, 1995). Finally, recent studies have suggested that ruminators have motivational deficits, which may inhibit them from taking proper action to solve their problems (Lyubomirsky et al., 1999) 
or to lift their moods (Lyubomirsky \& Nolen-Hoeksema, 1993; see also Irving, Snyder, \& Crowson, 1998; Salovey \& Birnbaum, 1989).

Finally, previous research has shown that women have greater tendencies to ruminate than do men (Butler \& Nolen-Hoeksema, 1994). Thus, women faced with a troubling symptom may be relatively more likely to ruminate and, as a result, to experience a host of cognitive and affective outcomes, leading them to delay obtaining a diagnosis for their symptoms. For example, one study showed that, among patients with cancer of the rectum, women were more likely than men to delay seeking care (Marshall \& Funch, 1986). These findings enhance the relevance of research on rumination to the delay of self-detected breast symptoms in women.

\section{RUMINATIVE RESPONSE STYLES THEORY AND DELAY OF PRESENTATION OF BREAST CANCER SYMPTOMS}

The results of research investigating the effects of self-focused rumination may be applied to illuminate and advance our understanding of the phenomenon of delay in help seeking for potentially dangerous health symptoms. Previous work has shown that when a ruminative style is combined with high negative affect and low positive affect, a vicious cycle emerges between mood, thinking, motivation, concentration, and problem solving (Lyubomirsky \& Tkach, 2004). This hypothesized process is depicted in Figure 1.

For example, as noted above, studies have shown that ruminative responses to bad moods encourage negatively biased thinking. Thus, after discovering a breast symptom, a woman may misinterpret it as punishment (e.g., "God gave me this for my sins") and/or make pessimistic self-attributions (e.g., "I deserve it"). Because ruminative responses specifically promote negatively biased thoughts about the self, a woman with a distorted interpretation of her symptom as God's punishment may "confirm" it for herself by recalling negative memories (e.g., "I have always gotten a raw deal in life, even as a child") and by making negative self-evaluations ("I am unattractive"). This, in turn, may lead a symptomatic individual to feel little control over her life and to make gloomy predictions about her future. Consequently, she may feel pessimistic and helpless (e.g., "It'll be malignant, so why bother?"), thereby amplifying her distress and ultimately preventing her from finding effective solutions to her problems (i.e., calling a doctor).

A woman's negatively biased thoughts may, in turn, interfere with concentration. For example, a ruminator may believe that it would be futile to call a healthcare professional about the breast symptom, and, due to her inability to concentrate, may need more time to make a decision 


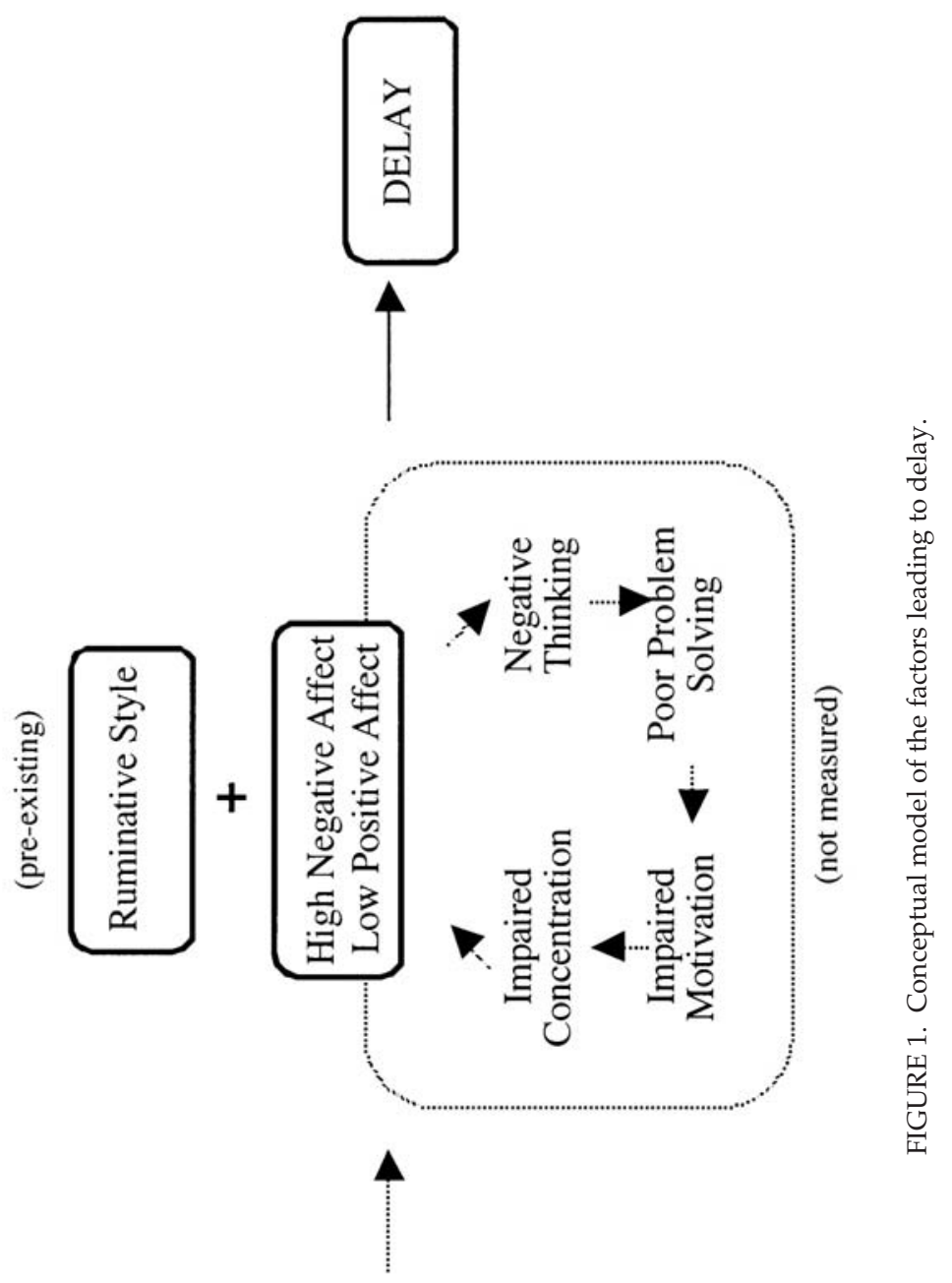

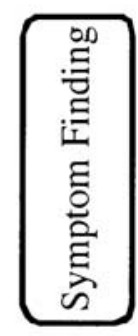


about what step to take next. Previous research has indicated that ruminators need relatively more time to implement plans to solve a problem (Ward et al., 2003) and may require an excessive amount of information before taking action (Davey, 1994; Tallis, Eysenck, \& Mathews, 1991).

Furthermore, studies have suggested that rumination in the context of a dysphoric mood leads people to show reduced motivation and commitment to carry out perfectly good solutions to their problems. Rumination maintains one's focus on one's distress, which may persuade individuals who are feeling sad or anxious that they lack the efficacy and wherewithal to take action, despite their recognition that such action is vital. Thus, after finding a breast lump, a woman may know what to do next, but may lack the energy to do so (e.g., "I can't bring myself to do it" or "I really don't feel like seeing anybody right now"), or may believe that she lacks the requisite ability or skill (e.g., "I don't even know where to start").

In sum, a ruminator who self-detects a breast lump may experience high negative affect and low positive affect, which is likely to trigger a vicious cycle involving a number of cognitive and motivational deficits. These deficits and the ruminator's distress will be self-reinforcing, ultimately promoting delay. In contrast, a non-ruminator-even when sad or anxious upon discovering a breast symptom-will not experience such a vicious cycle and thus will be relatively less likely to delay seeking help. Likewise, a ruminator who is not experiencing distress is also expected to be relatively less likely to show delayed symptom presentation.

\section{CURRENT STUDIES}

The purpose of the current research was to investigate whether self-focused rumination in the presence of negative affect leads to delay of health symptom presentation to healthcare professionals. Hence, two studies were designed to examine whether women with a ruminative style would wait longer to seek a diagnosis from a healthcare professional for a breast symptom than women without such a style. However, the anticipated cognitive and motivational deficits accompanying delay were beyond the scope of this research and were not measured.

In Study 1, female participants were asked to imagine that they had found a tiny breast lump that morning as they were taking their shower and were then asked to rate the likelihood that they would call the doctor immediately. Our hypothesis was that participants inclined to use a ruminative response style would be more likely to intend to delay (i.e., not call a doctor immediately) the presentation of their breast symptom than 
participants who do not tend to use such a style. We also expected individuals with the highest scores on the Ruminative Responses scale to delay the most.

In Study 2, we sought to increase the external validity of Study 1 by assessing actual breast cancer survivors' delay of presentation of their initial self-discovered breast symptoms to the healthcare system. In this study, members of breast cancer support groups were asked to recall the date that they first self-discovered their initial breast symptom(s) and the date that they first contacted a health professional about it. We hypothesized that breast cancer survivors with a greater ruminative response style would be relatively more likely to report that they had contacted a health professional about their breast symptom(s) at a later date. Again, as in Study 1, "extreme" ruminators were expected to delay the longest.

Finally, for both studies, we hypothesized that the relation between ruminative style and delay would be moderated by participants' affective responses at the time of symptom discovery. That is, differences between "ruminators" and "non-ruminators" were expected to be more pronounced when the discovery of a potential breast cancer symptom produces especially low positive affect and high negative affect.

\section{STUDY 1}

\section{METHOD}

\section{Overview}

Female ruminators and non-ruminators read a vignette in which they imagined they had just discovered a change in their breast. Participants then reported their intentions to seek a diagnosis for their imaginary breast symptom. Levels of positive affect, negative affect, and fear were assessed before and after the presentation of the vignette.

\section{Participants}

Two groups of women - university students aged 18 to $27(M=19.4)$ and university staff aged 36 to $61(M=47.7)$-participated in this study. Seventy-four undergraduate women enrolled in Introductory Psychology at a state university were recruited based on their scores for ruminative responses style, assessed in a mass-distributed questionnaire earlier in the academic quarter. Forty-one percent were Asian, 23\% Caucasian, 19\% Latino(a), 8\% African American, and 9\% "other." Additionally, 73 female staff at the same university (78\% Caucasian, $7 \%$ Latino(a), $5 \%$ African American, and 10\% "other") were recruited by electronic mail. A brief description of the study was e-mailed to all staff members, in which they were given the opportunity to have $\$ 10$ donated in their 
name to a breast cancer organization of their choice if they participated. The inclusion of older women in our sample allowed us to increase external validity by examining the responses of a group of women (i.e., those over 35 years of age) with relatively high risk of breast cancer (Keinan, Carmil, \& Rieck, 1991-1992; National Breast Cancer Foundation, 2004) and high risk of delay (Ramirez, Westcombe, Burgess, Sutton, Littlejohns, \& Richards, 1999), as well as those with relatively low breast cancer and delay risk (undergraduates). Similar age group distinctions have been used in studies of delay and breast cancer screening (e.g., Strax, 1976; Timko, 1987).

During the earlier questionnaire session, all participants completed the Response Style Questionnaire, which includes four scales-Ruminative Responses, Distracting Responses, Problem-Solving, and Sensation-Seeking. Only the Ruminative Responses subscale (RRS; e.g., Nolen-Hoeksema \& Morrow, 1991; Nolen-Hoeksema, Parker, \& Larson, 1994; Ward et al., 2003) was of interest in this study. RRS scores have been related to consistent ruminative responses to daily moods in diary studies (e.g., Nolen-Hoeksema, Morrow, \& Fredrickson, 1993; for further validity and reliability information, see Bagby \& Parker, 2001; Just \& Alloy, 1997). The RRS comprises 23 items describing chronic responses to negative mood that are focused on the self (e.g., "think about how alone you feel"), on symptoms (e.g., "think about your feelings of fatigue and achiness"), or on the possible consequences and causes of one's mood (e.g., "think about a recent situation, wishing it had gone better"). Participants were asked to rate how frequently they engaged in each of the relevant behaviors on 4-point Likert-type scales $(1=$ almost never, $4=$ almost always). All 23 items were combined and averaged to provide a single index for ruminative response style (Cronbach's $\alpha=$ .87 ), and those scoring in the upper quartile ("ruminators") and lower quartile ("non-ruminators") of our sample were recruited for this study.

In addition, following the procedure of previous rumination studies, all respondents were asked to complete the Beck Depression Inventory (BDI; Beck, 1967), and those whose scores were 16 and above were excluded from this study to ensure that mildly to moderately depressed participants were not part of our sample.

\section{Materials and Procedure}

A female experimenter administered all the materials for the study. Both the students and the staff participated individually. Each session was divided into four parts, each of which consisted of one packet of questionnaires. The experimenter remained in the laboratory only to give participants instructions, collect materials, and answer questions. A light bulb apparatus was used to allow participants to signal the experi- 
menter after completing each packet of materials. Instead of walking out of the room to call the experimenter, participants simply flicked a nearby switch, which was connected to a light bulb in the hallway. This procedure ensured that participants focused on the task at hand and were not influenced by outside distractions.

Affect. After reading and signing a consent form, participants completed the first packet of materials, which included a mood questionnaire-the Positive and Negative Affect Schedule (PANAS; Watson, Clark, \& Tellegen, 1988) —with 10 items measuring positive affect (PA; e.g., excited, enthusiastic) and 10 items measuring negative affect (NA; e.g., distressed, upset) on 5-point Likert-type scales. The two sets of 10 items were combined to provide two single indices of PA $(\alpha=.84)$ and NA $(\alpha=.84)$, respectively.

Next, respondents were asked to rate on 7 -point rating scales $(1=$ not at all, $7=$ very $m u c h$ ) the extent to which they were experiencing various fears "at this very moment." This "fear cascade" questionnaire was derived from a list originally proposed by Facione (1993) and consisted of 22 fears that had been related to breast cancer in previous studies (e.g., fear of ridicule, fear of loss of femininity, fear of loss of control, and fear of chemotherapy). These 22 cancer-related fears were combined to provide one single index for cancer-related fears $(\alpha=.96)$. In addition, 10 fears that were unrelated to cancer were included as fillers (e.g., fear of flying and fear of water). Finally, several filler questionnaires, which probed participants about different aspects of their health and lifestyle, were included to disguise the purpose of the study.

Breast lump vignette. Next, participants were presented with the following vignette, which they were asked to read and imagine experiencing themselves. This vignette was a modified version of one used by Timko (1987). She found that women's intentions regarding breast symptom help-seeking behavior after reading a similar vignette matched their previous health-seeking behaviors, such as visiting a doctor immediately after a physical symptom is noticed. In our modified vignette, the terms "class"/"school" and "work" were inserted for student and staff participants, respectively.

One morning, after the alarm goes off, you wake up and realize that you have to go to class (work). You take a shower before getting dressed to leave for school (work). As you are showering, you start washing your hair first and then soap your body. At this point you happen to feel a hard, tiny thickening on the edge of your left nipple. The bump is quite small, smaller than the size of a pea. You aren't sure there is anything unusual about the spot. You check the other breast and it looks fine. You quickly check the rest of your body and again everything seems fine. 
Aside from this change, you haven't noticed anything about your physical condition that is different from normal. You get out of the shower and think about what you should do. The thickening is tiny and you are feeling as well as you usually do.

Post-Vignette Questionnaire. Participants then completed the PANAS $(\alpha=.84$ for PA and $\alpha=.91$ for NA) and the fear questionnaire $(\alpha=.97)$ a second time, allowing us to measure post-vignette changes in affect and fear.

Intentions to seek a diagnosis. Participants were then asked to complete three items assessing their intentions to seek a diagnosis and their evaluation of the breast symptom as described in the vignette. The first item, which was the key dependent variable, asked respondents to rate the likelihood that they would decide to immediately call the doctor $(1=u n-$ likely, $7=$ likely). The second and third items, which were critical in determining how seriously participants treated the hypothetical scenario, asked them to rate the probability that the lump in "their" breast was a symptom of breast cancer $(1=$ unlikely, $7=$ likely $)$ and whether it represented a life-threatening condition $(1=$ not life-threatening, $7=$ life-threatening).

At the end of the session, participants were thoroughly debriefed. The entire study lasted approximately one hour.

\section{RESULTS AND DISCUSSION}

\section{Overview of Statistical Analyses}

We hypothesized that ruminators $(n=74)$ would delay longer in their intentions to seek a diagnosis from a healthcare professional than would non-ruminators $(n=73)$. Our primary analyses were $t$-tests comparing ruminators and non-ruminators on the critical dependent measure (i.e., intention to delay), as well as on three emotion-related variables previously related to delay - namely, negative affect, positive affect, and cancer-related fears. In addition, Pearson correlations were reported between each of these dependent variables and participants' scores on the RRS. Finally, we conducted regression and contrast analyses testing for the moderating role of affect.

\section{Preliminary Analyses}

Because two risk groups (young women and women over 35) were used in this study, 2 (high risk vs. low risk) $\times 2$ (ruminators vs. non-ruminators) analyses of variance (ANOVAs) were initially conducted to determine whether there were any significant interactions between risk group and ruminative style for any of our dependent 
variables. Only one significant interaction was found: Analyses revealed a Risk Group $\times$ Ruminative Status interaction for the index of fears at the beginning of the study, $F(1,131)=6.63, p=.01, r($ effect size $)=$ .22 , such that the difference in baseline fears between ruminators and non-ruminators was greater among the low-risk group than the high-risk group. In hindsight, this seemingly contradictory result is not surprising, as younger, primarily unmarried women - even though at lower risk for breast cancer-would be expected to be more self-conscious about their physical appearance than older women. Indeed, many of the fears in the fear index related to changes in physical appearance resulting from breast cancer, such as fear of losing a breast, fear of chemotherapy and radiation therapy (i.e., loss of hair), fear of surgeries, and fear of loss of femininity. These changes in physical appearance may be threatening to the prospect of finding a mate and creating a family. Thus, it is perhaps not surprising that younger ruminators would worry more about these concerns than older ruminators.

Because the fear index was not our primary outcome variable and was the only variable that yielded a significant interaction between group status and risk status, the two risk groups (younger women and older women) were collapsed for all subsequent analyses.

\section{Baseline Measures}

Baseline Affect. Results showed that, although ruminators and non-ruminators did not differ in their overall PA at the beginning of the study $(M s=3.01$ vs. $3.02 ; t<1, n s)$, ruminators reported significantly higher overall NA ( $\left.M^{\prime} s=1.41 \mathrm{vs} .1 .20\right), t(98)=2.78, p=.01, r=0.27$. These results are consistent with previous research, which has shown a link between rumination and negative affect, as well as negative thinking (see Lyubomirsky \& Tkach, 2004, for a review).

Baseline fear. Ruminators reported having significantly more fears related to breast cancer $(M s=2.98$ vs. 2.41$), t(122)=2.38, p=.02, r=0.21$, than did non-ruminators. Specifically, ruminators reported being relatively more afraid of unmanageable expenses, entering a dependent role, being dehumanized, isolation, and cancer. Again, these results are consistent with previous findings linking rumination with negative affect (see Lyubomirsky \& Tkach, 2004, for a review). Thus, our finding that ruminators are experiencing relatively high levels of different types of negative affect are not surprising.

\section{Post-Vignette Changes in Affect and Fear}

Changes in Affect. After reading the vignette, ruminators and non-ruminators did not significantly differ either in their changes in NA or PA (both $t^{\prime}$ s $<1, n s$ ). In hindsight, this finding is not surprising, as the 
initial reactions to the discovery of a hypothetical breast cancer symptom would be expected to reflect an increase in negative affect and a decrease in positive affect for many women, apart from ruminative status. Thus, regardless of ruminative style, participants on average showed significant decreases in PA $(M=-0.22, S D=0.53), t(146)=5.05, p<.001, r=.39$, and significant increases in NA $(M=0.55, S D=0.81), t(145)=8.20, p<.001, r=$ .56. These substantial changes in affect are important, as previous research suggests that the combination of ruminative response tendencies and negative emotions (or the lack of positive emotions) may trigger ruminators to engage in maladaptive behaviors-namely, to delay.

Changes in Fear. Ruminators and non-ruminators also did not differ in the changes they showed in their fears related to breast cancer from before to after reading the vignette $(t<1)$. Again, these results are not unexpected, as participants' initial reactions to the breast lump story would be expected to be similar regardless of their ruminative status. Thus, again, as expected, both ruminators and non-ruminators showed, on average, significant increases in fears related to breast cancer $(M=0.25$, $S D=0.81), t(130)=4.15, p<.001, r=.34$.

\section{Judgments of Vignette}

Ruminators and non-ruminators did not significantly differ in their ratings of whether the imagined lump represented a life-threatening condition $(\mathrm{t}<1.3)$, but they did differ in their judgments of whether the lump was a symptom of breast cancer ( $M s=4.93$ vs. 4.35$), t(142)=-2.24, p<.03$, $r=.18$.

\section{Delay in Seeking a Diagnosis}

Delay and Ruminative Status. After imagining that they have just discovered a breast lump, ruminators were expected to be more likely to delay in their intentions to seek a diagnosis from a healthcare professional than non-ruminators. Because ruminators and non-ruminators were found to differ significantly in whether they thought that the imagined breast lump was cancerous, and because of the imaginary nature of our design, it was necessary to control for this variable. Indeed, previous studies have shown that the failure to attribute a particular symptom to breast cancer plays a significant role in delayed symptom reporting (see Ramirez et al., 1999, for a review). Thus, this variable was used as a covariate in subsequent analyses. However, omission of the covariate yielded comparable significance levels and effect sizes.

Supporting our primary hypothesis, ruminators were indeed more likely to intend to delay - that is, to report being less likely to call a doctor immediately - than non-ruminators ( $M$ 's $=4.55$ vs. 5.50$), F(1,142)=$ $8.28, p<.01, r=0.23$ (see the top left panel of Figure 2). Notably, this 

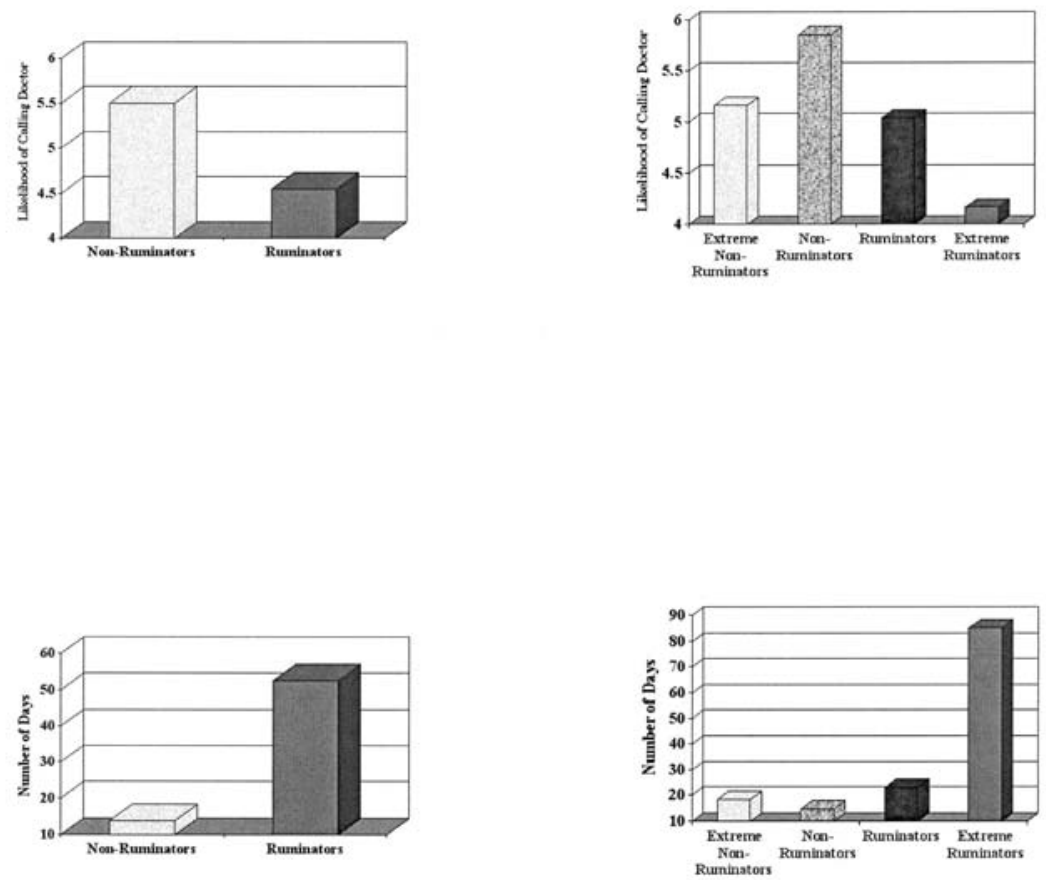

FIGURE 2. Top (Study 1): Mean ratings of intentions to immediately call the doctor of non-ruminators and ruminators (left panel) and of the four quartiles (right panel). Bottom (Study 2): Number of days between initial symptom detection and first contact with healthcare professional of non-ruminators and ruminators (left panel) and of the four quartiles (right panel).

group difference remained significant after controlling for baseline NA and baseline cancer fears, the two prevignette variables in which ruminators and non-ruminators were found to differ.

Confirming expectations, a visual inspection of the correlation between ruminative style (i.e., RRS scores) and likelihood of delay suggested a non-linear relationship. Thus, to investigate further the relation between ruminative tendencies and delay, we divided our primary independent variable into four quartiles. Supporting our prediction, planned contrast analyses revealed that extreme ruminators were significantly more likely to delay than the three other groups, $F(1,140)=$ $4.84, p<.01, r=.18$ (see Figure 2, top right panel). These results corroborate previous research, which has found that ruminators are relatively 
TABLE 1. Summary of Regression Analyses for Variables Predicting Delay in Study 1 $(N=147)$ and Study $2(N=70)$

\begin{tabular}{lcccrc}
\hline Predictor Variable & $\beta$ & $\boldsymbol{t}$ & $\boldsymbol{F}$ & Total $\boldsymbol{R}^{2}$ & $\Delta \boldsymbol{R}^{2}$ \\
\hline Study $\mathbf{1}$ & & & & & \\
$\quad$ Ruminative Style & -0.72 & $-2.16^{*}$ & $4.66^{*}$ & .03 & \\
$\quad$ Positive Affect & 0.58 & $1.75 \#$ & $4.78^{* *}$ & .06 & $.03^{*}$ \\
$\quad$ Ruminative Style $\times$ Positive Affect & 0.62 & 1.06 & $3.57^{*}$ & .07 & .01 \\
Study 2 & & & & & \\
$\quad$ Ruminative Style & 60.75 & $3.24^{* *}$ & $8.47^{* *}$ & .11 & \\
$\quad$ Positive Affect & -23.86 & $-2.76^{* *}$ & $8.05^{* * *}$ & .20 & $.09^{*}$ \\
$\quad$ Ruminative Style $\times$ Positive Affect & -40.41 & $-2.00^{*}$ & $6.95^{* * *}$ & .25 & $.05^{*}$ \\
\hline
\end{tabular}

Note. In Study 1, affect was indicated by changes in positive affect from before to after reading the symptom vignette. In Study 2, affect was indicated by retrospective positive affect at the time of symptom discovery. $\# p<.10 .{ }^{*} p<.05 .{ }^{* *} p<.01 .{ }^{* * *} p<.001$.

less confident, less satisfied, less committed, and need more time to implement their own plans to resolve a problem (Ward et al., 2003).

Delay and Affect. Interestingly, regardless of ruminative status, participants who were less likely to intend to delay were the ones who reported less NA at the beginning of the study $(r=-0.17, p<.05)$, and the highest increases in PA from before to after reading the vignette $(r=0.17$, $p<.05)$. These findings are not surprising, as past research has found that individuals suffering from a minor illness are more likely to report feeling capable of successfully carrying out illness-preventing and illness-alleviating behaviors if they are induced into a happy, rather than an unhappy, mood (Salovey \& Birnbaum, 1989). Similarly, those in our study who were in a relatively happy mood were less likely to delay - that is, more likely to take care of their health.

Moderation Analyses. Next, we investigated whether post-vignette changes in PA, NA, and cancer-related fears moderated the relationship between ruminative status and delay. Following procedures described in Baron and Kenny (1986), we conducted a set of regression analyses, predicting delay from (1) ruminative style, (2) changes in affect, and (3) the cross-product term between (centered) rumination scores and affect change scores.

The top of Table 1 displays the results of these analyses for changes in PA as the moderator variable. Although ruminative style and changes in PA each predicted intentions to delay, the interaction between these two variables was not significant. However, given our explicit interest in the moderating effects of affect, we examined the effects of ruminative style 
on delay at the two key levels of PA change-high and low-generally corresponding to increases in PA $(M=0.21)$ vs. decreases in PA $(M=$ -0.62 ). To this end, planned comparisons revealed a significant effect of ruminative style on delay under conditions of decreased PA $(M s=4.30$ vs. 5.30 for ruminators and non-ruminators, respectively), $t(141)=$ $-2.07, p<.05, r=0.17$, but not under conditions of increased PA (Ms = 5.08 vs. 5.43 ), $t<1$, ns. (See Stalder \& Baron, 1998, for an identical approach.) This finding can be more clearly observed in the top panel of Figure 3-that is, differences between ruminators and non-ruminators are stronger when participants experienced general decreases in positive moods after reading the symptom vignette than when participants experienced slight increases in positive moods in the same situation.

Interestingly, parallel analyses testing changes in NA and changes in cancer-related fears as moderators indicated that neither of these variables significantly moderated the rumination-delay relationship. Thus, positive emotions appear to play a more crucial role in the link between ruminative style and intention to delay than do negative emotions.

\section{CONCLUSIONS}

The results of prior studies (e.g., Michie, Dormandy, French, \& Marteau, 2004; Montano, \& Taplin, 1991) indicate that intentional help-seeking or health behaviors often match actual behaviors. Thus, although the primary findings of this study - namely, those concerned with the relation between ruminative status and delay-were obtained using a hypothetical symptom discovery paradigm, they are nevertheless promising. However, the natural next step was to investigate the health-seeking behavior of actual breast cancer survivors. That is, would women with ruminative tendencies who discover a real symptom of breast cancer be more likely to delay the presentation of this symptom to a healthcare professional than women without such tendencies? This question was addressed in Study 2.

\section{STUDY 2}

METHOD

\section{Overview}

Women survivors of breast cancer were recruited from cancer support groups to complete instruments assessing their experiences with their breast cancer symptom finding. Participants completed a measure of ruminative style, reported on their affective responses to symptom finding, and recalled the dates related to their symptom finding. 

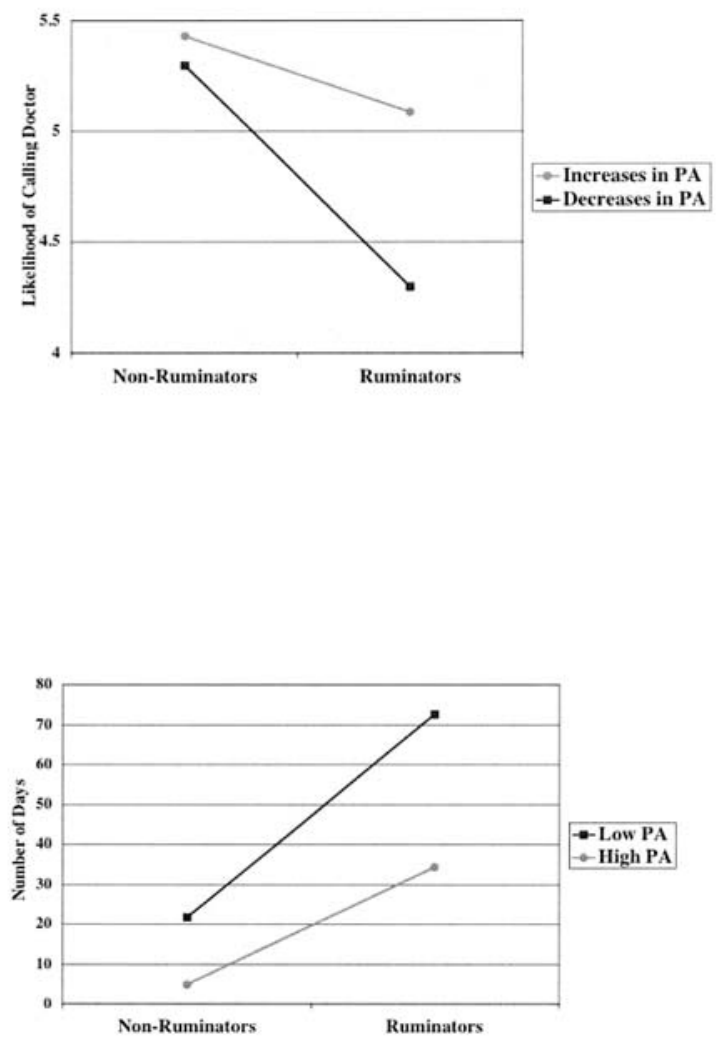

FIGURE 3. Top (Study 1): Interaction effect between ruminative style and changes in positive affect (PA), predicting intentions to immediately call the doctor. Bottom (Study 2): Interaction effect between ruminative style and positive affect, predicting number of days between initial symptom detection and first contact with healthcare professional.

\section{Participants and Procedure}

In this study, 139 women members of breast cancer support groups, ages ranging from 32 to $86(M=54.9)$, participated. The majority of this sample was recruited during support group meetings. With previous approval from group facilitators, one of two experimenters visited the groups, gave a brief presentation about the study, and distributed a questionnaire. Some of the women completed and returned the questionnaire immediately, while others were given stamped, addressed envelopes to send the completed questionnaires back to the experimenter, at their own leisure. The remainder of the sample (31\%) was recruited 
from online breast cancer support groups. We e-mailed a description of the study and asked interested online members to provide their mailing addresses. These women were then sent a copy of the questionnaire, along with a stamped, addressed envelope. Of the 200 women who were either mailed or provided the questionnaire in person, 139 (69.5\%) completed and returned it. Thus, the response rate was excellent.

Fifty-seven percent of our participants held professional jobs, $28 \%$ were retired, and $15 \%$ were homemakers; they had a mean of 2.6 children. The participants' ethnic distribution was as follows: $84 \%$ European American, 6\% Native American, and 7\% "other." One percent had finished some high school, $21 \%$ were high school graduates, $27 \%$ had completed some college, 35\% were college graduates, and 15\% had graduate or professional degrees.

Importantly, $50 \%$ of the sample - a total of 70 women-reported that they had self-detected their symptom(s). When asked about the nature of these initially discovered breast cancer symptoms, 38 of the 70 women indicated a breast lump or thickening, 4 indicated nipple change or discharge, 1 indicated pain, 24 indicated multiple symptoms, and 3 indicated "other." Thus, for the purposes of this study, which was concerned with help-seeking behavior for self-detected symptoms, data from only these 70 women were analyzed. Notably, none of these women scored 16 or above on the BDI and thus did not need to be excluded.

Participants were encouraged to contact the experimenter with any questions regarding the study. They were remunerated for their time in the form of a donation of $\$ 10$ on their behalf to the National Cancer Institute or the breast cancer organization of their choice.

\section{Measures}

Affective Responses. After reading and signing the consent form, participants completed the PANAS (Watson et al., 1988). As in the first study, the two sets of 10 items were combined to provide two single indices of PA $(\alpha=.92)$ and NA $(\alpha=.77)$, respectively. In addition to using the PANAS to rate their current affect at the time of completing the questionnaire, respondents also retrospectively rated their affect at the time they first discovered their breast cancer symptom(s) ( $\alpha \mathrm{s}=.79$ and .87 for retrospective PA and retrospective NA, respectively). Due to time constraints, fears were not measured in this study.

Ruminative Style. Next, participants completed the RRS. As before, all 23 items were averaged to provide a single index for ruminative re-

1. In both studies, whether participants were classified via median split versus quartiles yielded virtually identical results. 
sponse style $(\alpha=.91)$. Participants were classified as either ruminators or non-ruminators using a median split of their scores. ${ }^{1}$

Delay in Help Seeking. Participants then provided the dates of their breast cancer symptom finding and subsequent care seeking. Specifically, they reported the date that they first noticed their breast cancer symptom(s) and the date they first contacted their healthcare professional. ${ }^{2}$ The following instructions were also included to assist participants in remembering these events:

Sometimes it is difficult to remember a specific date and thinking of an important date in your life around the time you first noticed your breast symptom(s) - for example, your birthday or a family member's birthday-may help.

Additionally, participants were provided with a calendar of the previous three years to help them select the correct dates. Delay was operationalized as the number of days elapsed between participants' reported date of symptom detection and date of first contact with the health care system.

\section{RESULTS AND DISCUSSION}

\section{Overview of Statistical Analyses}

In this study, we were concerned with how ruminators and non-ruminators differed in their responses to the self-detection of their breast cancer symptoms. Accordingly, as in Study 1, t-test and correlational analyses were conducted to examine differences between ruminators and non-ruminators' scores on the primary outcome variables. Furthermore, once again, regression and contrast analyses were conducted to test the moderating role of affect in the link between rumination and delay.

\section{Baseline Variables}

Baseline Affect. As in Study 1, at the time of the study, ruminators reported significantly higher overall NA than did non-ruminators $(M s=$ 1.89 vs. 1.49$), t(58)=2.22, p<.05, r=0.27$. Analyses also showed that ruminators reported marginally lower baseline overall PA than did non-ruminators $(M s=3.23$ vs. 3.61$), t(65)=1.70, p<.10, r=-0.20$.

Affect at the Time of Symptom Discovery. Ruminators and non-ruminators did not differ significantly in their retrospectively reported PA

2. Unfortunately, unlike in Study 1, we failed to ask participants whether they believed at the time of symptom discovery that their symptom was an indicator of breast cancer. 
$(M s=2.71$ vs. 2.80$)$ or NA $(M s=2.63$ vs. 2.67$)$ at the time they discovered their symptoms (both $t s<1$ ). These results parallel those of Study 1 , which found no differences between ruminators and non-ruminators in their immediate responses to the discovery of a (hypothetical) breast symptom. Thus, this naturalistic study also indicates that initial reactions to a breast symptom self-discovery would be expected to be relatively negative for many women, regardless of their ruminative status. Additionally, these results bolster the validity of participants' affect ratings, indicating that respondents were able to differentiate between how they felt at the time of our study versus how they felt at the time of symptom discovery. That is, ruminators and non-ruminators differed significantly in their current affect (i.e., at the time of the study), but not in their retrospective affect.

\section{Delay in Seeking a Diagnosis}

Supporting our primary hypothesis, ruminators delayed the presentation of their breast cancer symptoms significantly longer than did non-ruminators $(M=52.5$ [96.3] vs. 13.9 [22.8] days), $t(40)=2.36, p=.02$, $r=0.350$-indeed, the group difference in delay was longer than a month (see the bottom left panel of Figure 2). Notably, 25 (67\%) ruminators-versus $5(16 \%)$ non-ruminators-delayed longer than a month. Additionally, because our data for the "delay" variable showed significant group differences in variances, $t(36)=1.91, p=.06$, and, thus, potentially violated the homogeneity of variance assumption, we converted them using a square root transformation. The results of a $t$-test comparing ruminators and non-ruminators were virtually identical with the transformed data, $t(54)=2.33, p=.02, r=.30$.

Furthermore, following the procedure of Study 1, to decompose this finding further, the sample was subdivided into four quartiles for ruminative scores - that is, extreme ruminators, ruminators, non-ruminators, and extreme non-ruminators. As in Study 1, extreme ruminators were significantly more likely to delay than the three other groups, $F(1,64)=$ $7.70, p<.01, r=.33$ (see the bottom right panel of Figure 2).

These results support our primary hypothesis that breast cancer survivors who have ruminative tendencies would report having waited longer to present their self-discovered breast symptom to a health professional than would breast cancer survivors who do not have such a style. Overall, $19 \%$ of our participants delayed three months or longer, a find-

3. The average interval between symptom discovery and participation in our study was 2.77 years $(S D=5.53)$; ruminators and non-ruminators did not differ significantly on this variable. Furthermore, the type of symptom that our participants discovered was neither significantly related to delay nor to ruminative status. 
ing consistent with previous studies (e.g., Facione et al., 2002). However, our findings reveal that only "extreme" ruminators appear to be inclined to delay in response to self-detection of a breast symptom.

Delay and Affect. Similar to the results of Study 1, a negative correlation was found between delay and PA at the time of symptom discovery $(r=-0.39, p<.001)$, suggesting that the more upbeat participants reported feeling at the time of discovering their breast cancer symptoms, the less likely they were to delay the presentation of their symptoms to a healthcare professional. Again, this finding is not surprising, as previous research has found a link between induced positive mood and adaptive health behaviors (Salovey \& Birnbaum, 1989).

Moderation Analyses. Again, following Baron and Kenny (1986), we tested whether PA and NA at the time of breast symptom discovery moderated the rumination-delay relationship.

The bottom portion of Table 1 shows the results of regression analyses testing PA as the moderator variable. Importantly, ruminative style, PA, and the interaction between ruminative style and PA all significantly predicted the number of days between symptom discovery and symptom presentation. Thus, the results indicate that the interaction between ruminative style and PA at the time of symptom discovery accounts for a significant amount of the variance in predicting delay, suggesting that PA serves as a moderator of the rumination-delay relationship. Further bolstering this finding, as in Study 1, the results of planned contrasts showed the effect of ruminative style on delay to be significant when PA during symptom discovery was low ( $M s=72.4$ vs. 21.5 for ruminators and non-ruminators, respectively-i.e., a difference of almost 51 days), $t(63)=2.04, p<.05, r=0.25$, but failing to reach significance when PA was high ( $M s=34.3$ vs. 4.7 -i.e., a difference of about 30 days), $t<1.2, n s$. The bottom panel of Figure 3 displays this finding graphically, demonstrating that differences between non-ruminators and ruminators were more pronounced when participants recalled experiencing relatively low PA when they first discovered their breast cancer symptom ( $M$ for $\mathrm{PA}=2.06$ on a 5-point scale) than when they recalled experiencing relatively high PA ( $M=3.51$ on a 5 -point scale).

Paralleling the results of Study 1, moderation analyses indicated that retrospective $N A$ was not a significant moderator of the rumination-delay relationship. Thus, again, we found that positive affect, but not negative affect, appears to play a key role in mitigating the harmful effects of ruminative style on delay.

Meta-Analysis

A meta-analysis was conducted to combine and compare the results of Study 1 and Study 2 regarding the primary dependent variable (delay) 
and determine whether the two sets of results were consistent with each other. A comparison of both the $p$ values $(Z=-0.12, n s)$ and the effect sizes $(Z=1.46, n s)$ revealed that the results of Studies 1 and 2 did not significantly differ from one another. Additionally, and not surprisingly, combining either the $p$ values $(Z=2.79, p=.003)$ or the effect sizes $(r=$ $0.25, p>.01$ ) of our two studies led to results that were even more statistically significant than analyzing them separately.

\section{GENERAL DISCUSSION}

The hypothesis that women with ruminative tendencies would be more likely to delay the presentation of health symptoms than women without such tendencies was supported in two different studies. In Study 1, after being asked to imagine that they had found a breast symptom that morning while taking their shower, ruminators were less likely to report intending to call the doctor immediately than were non-ruminators. In Study 2, breast cancer survivors with a ruminative response style recalled waiting longer to present their initial self-discovered breast symptom to a health professional than did survivors without such a style. Indeed, $67 \%$ of respondents who delayed 30 days or more were ruminators (versus $16 \%$ of non-ruminators). Notably, studies show that delays of three months can impact breast cancer prognosis (Arndt, Stürmer, Stegmaier, Ziegler, Dohm, \& Brenner, 2002; Kothari \& Fentiman, 2003; Richards, Westcombe, Love, Littlejohns, \& Ramirez, 1999). Thus, our findings from Study 1 corroborate our Study 1 results and bolster our confidence in the external validity of both studies.

Furthermore, both studies found modest to strong evidence that affective responses to the discovery of a hypothetical symptom (Study 1) or a real one (Study 2) moderate the relation between ruminative style and delay. Interestingly, this evidence concerned positive emotions only. That is, differences between ruminators and non-ruminators were weaker when women were experiencing at least some PA at the time of symptom discovery. In sum, our findings suggest that the experience of PA may buffer the negative effects of ruminative style on delay, possibly by short-circuiting the rumination likely to be triggered by the stressful experience of symptom finding. Perhaps-even in a woman with ruminative tendencies-positive emotions "undo" the effects of negative emotions (Fredrickson, Mancuso, Branigan, \& Tugade, 1998; Fredrickson et al., 2000) and help galvanize her to take action. Indeed, the high arousal positive emotions assessed with the PANAS in our two studies-e.g., feeling interested, strong, inspired, energetic - may be especially valuable during ambiguous but critical situations like the initial 
discovery of potential symptoms. Furthermore, PA can fuel optimism and self-confidence, which may prompt women to minimize the threatening aspects of such situations and, instead, focus on the steps they can take to move forward. In sum, we do not yet understand why PA appears to play a more significant role in the rumination-delay relationship than does NA. Future research is needed to replicate these findings and advance our knowledge of the affective processes underlying delay. To be sure, the intriguing suggestion that positive emotions may be as much or more functional as negative emotions deserves further attention (cf. Fredrickson, 2001; Seligman \& Csikszentmihalyi, 2000).

Despite the somewhat unexpected results regarding PA, our findings are consistent with the argument that it is an enhanced negative mood (and reduced positive mood), coupled with an existing ruminative style, that lead to deficits in implementation of instrumental action (Ward et al., 2003) - that is, delay. Specifically, we speculate that the essential role of PA consists of disrupting or limiting the damaging vicious cycle depicted in Figure 1. As mentioned earlier, prior work has suggested that, when a ruminative style is combined with high negative affect and low positive affect, a vicious cycle is activated between mood, thinking, motivation, concentration, and problem-solving (Lyubomirsky \& Tkach, 2004). For example, while experiencing this vicious cycle, ruminators who self-detect a breast symptom may exhibit negatively biased thinking (Lyubomirsky et al., 1998, 1999; Lyubomirsky \& Nolen-Hoeksema, 1995; e.g., "It must be malignant" or "I look terrible"). These negatively biased thoughts may, in turn, interfere with concentration (Lyubomirsky et al, 2003; e.g., "I need more time to think of what to do"). Furthermore, these processes are associated with poor problem solving (e.g., failure to develop a plan for contacting a doctor immediately; Lyubomirsky et al., 1999; Lyubomirsky \& Nolen-Hoeksema, 1995) and low motivation (e.g., "I don't feel like talking to any doctor"; Lyubomirsky et al., 1999; Lyubomirsky \& Nolen-Hoeksema, 1993). Finally, all of these cognitive and motivational deficits may enhance distress, which, in turn, may promote further delay (see Figure 1). The following statement, made by a breast cancer survivor with a ruminative style who delayed seeking treatment for her breast symptom, illustrates in part this vicious cycle:

I was frightened. I knew it was cancer. It was going to change my life as well as my family. I waited until after my son graduated from H.S., after my daughter was done with showing horses, my oldest son got a job. I wanted not to ruin their life. 


\section{LIMITATIONS AND FUTURE QUESTIONS}

A notable limitation of the first study is that intentional diagnosis-seeking behaviors do not necessarily equate with actual diagnosis-seeking behaviors. However, we are encouraged by several previous findings. First, participants' self-reports of past health-seeking behaviors (e.g., consulting with a physician on a regular basis, going to the doctor right away after noticing a physical symptom, and seeking physician care regardless of health symptoms) have been found to match their intentional health-seeking behaviors in a recent study from our laboratory (i.e., they were more likely to intend to call the doctor immediately; Kasri, 2001). Moreover, these findings support previous research, which has provided evidence that intentional health behaviors correspond with actual health behaviors (Godin \& Kok, 1996). Second, because this concern was critical, we addressed it by assessing breast cancer survivors' actual health-seeking behaviors in a second study. The results of Study 2 corroborated the findings of Study 1 ; that is, in both studies, ruminators were more likely to delay than were non-ruminators. However, future research should determine whether members of breast cancer support groups - the sample we used in Study 2-are representative of all women with breast cancer, by using more diverse and generalizable samples of cancer survivors.

Of course, due to the correlational nature of both studies, we cannot rule out the possibility that delay behavior may magnify ruminative tendencies, instead of the reverse. Indeed, the negative consequences associated with delaying can certainly feed and encourage negatively biased and repetitive thinking. However, experimental designs, which could establish causality, are obviously not possible, as it would be unethical to induce some people to delay presenting their symptoms, or to induce some people to ruminate following symptom discovery. An alternative approach for future researchers would be to manipulate ruminative tendencies and then assess people's general inclinations to delay.

A further concern was the two studies' sole reliance on self-reports. For example, the independent variable (response style to negative emotions) and the dependent variables (affect, fears, delay) may have been subject to shared sources of bias and/or confounding. Another potential problem is that, because of social desirability concerns, our participants might have minimized their self-reported delay (or intentions to delay) so that they could feel good about themselves and not feel guilty. However, in both studies, respondents admitted to substantial amounts of delay (or delay intentions), and the results indicated that ruminators and non-ruminators significantly differed in their delay responses. 
Thus, participants appeared to have been reasonably truthful. Furthermore, we have no reason to expect ruminators and non-ruminators to differ in their needs for social desirability. In sum, in spite of its limitations, the use of self-report was the best method available to us. In future studies, investigators could additionally ask respondents' close relatives and friends to assess their response styles and to confirm dates of symptom detection and diagnosis seeking. Also, future researchers could obtain records of doctor-patient contacts by contacting respondents' primary physicians.

Additionally, Study 2 relied on retrospective self-reports. That is, cancer survivors were asked to recall when they first self-discovered their breast symptom(s), how they felt at the time, and when they first sought diagnosis. Such reports are subject to retrospective memory biases, including the effects of present-day mood, state of health, and prognosis. However, in part to increase our confidence in the accuracy of participants' recall of the relevant dates, we provided them with additional instructions aimed to boost their memories—namely, asking participants to recall an important date, such as their own or a loved one's birthday around the time they first self-discovered their breast symptom(s). This was done to ensure that respondents focused on the appropriate time frame surrounding their breast symptom self-discovery and to increase the likelihood of accuracy. Moreover, as previously mentioned, participants appeared to be capable of differentiating between how they felt during the study and how they felt at the time of their self-detected breast symptom. These findings are encouraging, as they suggest not only that participants could accurately remember how they felt at the time of their breast symptom discovery, but they also bolster our confidence in the validity of all our data in this study.

To increase external validity even more, future investigations could recruit women awaiting biopsies for a self-discovered breast lump. This procedure could potentially catch women at the time that they are seeking help, which would greatly reduce retrospective memory biases regarding the dates of symptom discovery and presentation to the health care system. (Unfortunately, it is close to impossible to catch women at the time of symptom discovery.) This design could also be used to investigate ruminators' biased thinking, which was not explored in the studies reported here. For example, by collecting "thought samples," researchers could examine which negatively-biased thoughts ruminators $\mathrm{d}$ well on before seeking diagnosis. As mentioned earlier, it has been argued that ruminators become so overwhelmed with their repetitive, negative thoughts, that they may have difficulty "registering" new information (Lyubomirsky et al., 2003), and therefore, may be unable to concentrate and to take appropriate action for whatever problem they 
are facing (i.e., seek diagnosis). Such investigations would advance our knowledge of the cognitive processes underlying the phenomenon of delay.

\section{CONCLUSIONS AND IMPLICATIONS}

The studies reported here expand previous research on delay by drawing on the ruminative response style theory. Our findings warn us of the dangers of self-focused rumination and provide clues to the underlying processes-both affective (e.g., high negative affect and low positive affect) and cognitive (e.g., thinking, problem solving, motivation, concentration) - associated with delay. Additionally, this research advances prior work on rumination by exploring the consequences of ruminative styles in the domain of health.

Importantly, previous research has shown that when people are induced to distract from their negative moods, they show more optimistic inferences, attributions, and predictions, more positive self-evaluations and memories, and increased perceptions of control and ability to solve problems (see Lyubomirsky \& Tkach, 2004, for a review). These findings suggest that such techniques as cognitive-behavioral therapy may help teach women with ruminative response styles to distract their attention away from negative moods upon discovery of a potential breast cancer symptom. Additionally, positive affect interventions (Lyubomirsky, Sheldon, \& Schkade, 2005) may help hold rumination in check, in part by undoing the effects of negative emotions. In sum, although costly, these types of techniques may alleviate negative moods and promote positive moods. The improved affect, as a result, may prompt women ruminators to think clearly of solutions to their problems (i.e., seek evaluation of their breast symptom from a doctor) and, even more important, to act on these solutions. Thus, elements of cognitive-behavioral therapy or related methods may be necessary to integrate into breast self-examination media campaigns. Such campaigns could warn all women - and especially those at risk for ruminating - of the different negative affective reactions they might have when finding a breast cancer symptom and include messages to teach them skills to manage their likely emotions in response to a "positive" result. In short, women should be urged to contravene the ruminating process by seeking help immediately after discovering a breast symptom.

Finally, and most important, our results are significant in light of research findings that the longer a woman waits to seek a diagnosis after discovering a breast symptom, the more advanced, and therefore the more fatal, her cancer will be if her symptom is malignant (Funch, 1984; Levy, 1983; Neave et al., 1990; Richards et al., 1999; Rossi et al., 1990; 
Wilkinson et al., 1979). Thus, by educating health care professionals, as well as women at risk for rumination, of the potential dangers of a ruminative response style and possible ways to attenuate it, the number of fatalities related to breast cancer may be reduced.

\section{REFERENCES}

Ajekigbe, A. T. (1991). Fear of mastectomy: The most common factor responsible for late presentation of carcinoma of the breast in Nigeria. Clinical Oncology 3, 78.

Andersen, B.L., \& Cacioppo, J. T. (1990). Secondary and tertiary prevention: Psychophysiological comparison theory and its role in understanding patient delay. Cancer Prevention, 1, 122-126.

Andersen, B. L., \& Cacioppo, J. T. (1995). Delay in seeking a cancer diagnosis: Delay stages and psychophysiological comparison processes. British Journal of Social Psychology, 34, 33-52.

Arndt, V., Stürmer, T., Stegmaier, C., Ziegler, H., Dhom, G., \& Brenner, H. (2002). Patient delay and stage of diagnosis among breast cancer patients in Germany-a population based study. British Journal of Cancer, 10, 1034-1040.

Bagby, R. M., \& Parker, J. D. A. (2001). Relation of rumination and distraction with neuroticism and extraversion in a sample of patients with major depression. Cognitive Therapy and Research, 25, 91-102.

Baron, R. M., \& Kenny, D. A. (1986). The moderator-mediator variable distinction in social psychological research: Conceptual, strategic, and statistical considerations. Journal of Personality and Social Psychology, 51, 1173-1182.

Beck, A. T. (1967). Depression, clinical, experimental, and theoretical aspects. New York: Harper \& Row.

Butler, L. D., \& Nolen-Hoeksema, S. (1994). Gender differences in depressed mood in a college sample. Sex Roles, 30, 331-346

Davey, G.C.L. (1994). Worrying, social problem-solving abilities, and social problem-solving confidence. Behavior Research and Therapy, 32, 327-330.

De Nooijer, J., Lechner, L., \& De Vries, H. (2001). Help-seeking behaviour for cancer symptoms: Perceptions of patients and general practitioners. Psycho-Oncology, 10, $469-478$.

Elwood, J. M., \& Moorehead, W.P. (1980). Delay in diagnosis and long-term survival in breast cancer. British Medical Journal, 280, 1291-1294.

Facione, N. C. (1993). Delay versus help seeking for breast cancer symptoms: A critical review of the literature on patient and provider delay. Social Science and Medicine, 36, $1521-1534$.

Facione, N. C., Miaskowski, C., Dodd, M. J., \& Paul, S. M. (2002). The self-reported likelihood of patient delay in breast cancer: New thoughts for early detection. Preventive Medicine, 34, 397-407.

Fredrickson, B. L. (2001). The role of positive emotions in positive psychology: The broaden-and-build theory of positive emotions. American Psychologist, 56, 218-226.

Fredrickson, B. L., \& Levenson, R. W. (1998). Positive emotions speed recovery from the cardiovascular sequelae of negative emotions. Cognition and Emotion, 12, 191-220.

Fredrickson, B. L., Mancuso, R. A., Branigan, C., \& Tugade, M. M. (2000). The undoing effect of positive emotions. Motivation and Emotion, 24, 237-258. 
Funch, D. P. (1984). The role of patient delay in the evaluation of breast self-examination. Journal of Psychosocial Oncology, 2, 31-39.

Godin, G., \& Kok, G. (1996). The theory of planned behavior: A review of its applications to health-related behaviors. American Journal of Health Promotion, 11, 87-98.

Grunfeld, E. A., Hunter, M. S., Ramirez, A. J., \& Richards, M. A. (2003). Perceptions of breast cancer across the lifespan. Journal of Psychosomatic Research, 54, 141-146.

Irving, L. M., Snyder, C. R., \& Crowson, J. J. (1998). Hope and coping with cancer by college women. Journal of Personality, 66, 195-214.

Just, N., \& Alloy, L. B. (1997). The response styles theory of depression: Tests and an extension of the theory. Journal of Abnormal Psychology, 106, 221-229.

Kasri, F. (2001). Ruminative response styles and delay of presentation of health symptoms. Dissertation Abstracts International: Section B: The Sciences \& Engineering, 62, 2991.

Keinan, G., Carmil, D., \& Rieck, M. (1991-92). Predicting women's delay in seeking medical care after discovery of a lump in the breast: The role of personality and behavior patterns. Behavioral Medicine, 17, 177-183.

Kothari, A., \& Fentiman, I. S. (2003). Diagnostic delays in breast cancer and impact on survival. International Journal of Clinical Practice, 57, 200-203.

Leventhal, E. A. (1970). Findings and theory in the study of fear communications. In L. Berkowitz (Ed.), Advances in experimental social psychology (Vol. 5, pp. 119-186). San Diego, CA: Academic Press.

Leventhal, H., \& Diefenbach, M. (1991). The active side of illness cognition. In J. A. Skelton \& R. T. Croyle (Eds.), Mental representation in health and illness (pp. 247-272). New York: Springer-Verlag.

Levy, S. M. (1983). Host differences in neoplastic risk: Behavioral and social contributors to disease. Health Psychology, 2, 21-44.

Lyubomirsky, S., Caldwell, N. D., \& Nolen-Hoeksema, S. (1998). Effects of ruminative and distracting responses to depressed mood on the retrieval of autobiographical memories. Journal of Personality and Social Psychology, 75, 166-177.

Lyubomirsky, S., Kasri, F., \& Zehm, K. (2003). Dysphoric rumination impairs concentration on academic tasks. Cognitive Therapy and Research, 27, 309-330.

Lyubomirsky, S., \& Nolen-Hoeksema, S. (1993). Self-perpetuating properties of dysphoric rumination. Journal of Personality and Social Psychology, 65, 339-349.

Lyubomirsky, S., \& Nolen-Hoeksema, S. (1995). Effects of self-focused rumination on negative thinking and interpersonal problem solving. Journal of Personality and Social Psychology, 69, 176-190.

Lyubomirsky, S., Sheldon, K. M., \& Schkade, D. (2005). Pursuing happiness: The architecture of sustainable change. Review of General Psychology, 9, 111-131.

Lyubomirsky, S., \& Tkach, C. (2004). The consequences of dysphoric rumination. In C. Papageorgiou \& A. Wells (Eds.), Rumination: Nature, theory, and treatment of negative thinking in depression (pp. 21-41). Chichester, England: John Wiley \& Sons.

Lyubomirsky, S., Tucker, K. L., Caldwell, N. D., \& Berg, K. (1999). Why ruminators are poor problem solvers: Clues from the phenomenology of dysphoric rumination. Journal of Personality and Social Psychology, 77, 1041-1060.

MacFarlane, M. E., \& Sony, S. D. (1992). Women, breast lump discovery, and associated stress. Health Care for Women International, 13, 23-32.

Machiavelli, M., Leone, B., Romero, A., Perez, J., et al. (1989). Relation between delay and survival in 596 patients with breast cancer. Oncology, 46, 78-85.

Magarey, C. J., Todd, P. B., \& Blizard, P. J. (1977). Psychosocial factors influencing delay and breast self-examination in women with symptoms of breast cancer. Social Sciences Medicine, 11, 229-232. 
Marshall, J. R., \& Funch, D. P. (1986). Gender and illness behavior among colorectal cancer patients. Women and Health, 11, 67-82.

Michie, S., Dormandy, E., French, D. P., \& Marteau, T. M. (2004). Using the theory of planned behaviour to predict screening uptake in two contexts. Psychology and Health, 19, 705-718.

Montano, D. E., \& Taplin, S. H. (1991). A test of an expanded theory of reasoned action to predict mammography participation. Social Science and Medicine, 32, 733-741.

Mor, V., Guadagnoli, E., \& Wool, M. (1987). An examination of the concrete service needs of advanced cancer patients. Journal of Psychosocial Oncology, 5, 1-17.

National Breast Cancer Foundation. (2004). Signs \& symptoms: Overview. Retrieved June 25, 2004 from the World Wide Web: http://nationalbreastcancer.org/ signs_and_symptoms/index.html.

National Cancer Institute. (2003, June 4). What you need to know about breast cancer. Retrieved August 20, 2003 from the World Wide Web: http:/ / www.cancer.gov/cancerinfo/ wyntk/breast.

Neave, L. M., Mason, B. H., \& Kay, R. G. (1990). Does delay in diagnosis of breast cancer affect survival? Breast Cancer Research Treatment, 15, 103-108.

Nolen-Hoeksema, S. (1991). Responses to depression and their effects on the duration of depressive episodes. Journal of Abnormal Psychology, 100, 569-582.

Nolen-Hoeksema, S. (2003). Women who think too much: How to break free of overthinking and reclaim your life. New York: Henry Holt and Company.

Nolen-Hoeksema, S., \& Morrow, J. (1991). A prospective study of depression and posttraumatic stress symptoms after a natural disaster: The 1989 Loma Prieta earthquake. Journal of Personality and Social Psychology, 61, 115-121.

Nolen-Hoeksema, S., Morrow, J., \& Fredrickson, B. L. (1993). Response styles and the duration of episodes of depressed mood. Journal of Abnormal Psychology, 102, 20-28.

Nolen-Hoeksema, S., Parker, L. E., \& Larson, J. (1994). Ruminative coping with depressed mood following loss. Journal of Personality and Social Psychology, 67, 92-104.

Ramirez, A. J., Westcombe, A. M., Burgess, C. C., Sutton, S., Littlejohns, P., \& Richards, M. A. (1999). Factors predicting delayed presentation of symptomatic breast cancer: A systematic review. Lancet, 353, 1127-1131.

Richards, M. A., Smith, P., Ramirez, A. J., Fentiman, I. S., \& Rubens, R. D. (1999). Stage and delay in breast cancer diagnosis by race, socio-economic status, age, and year. British Journal of Cancer, 79, 858-864.

Richards, M. A., Westcombe, A. M., Love, S. B., Littlejohns, P., \& Ramirez, A. J. (1999). Influence of delay on survival in patients with breast cancer: A systematic review. Lancet, $353,1119-1126$.

Richardson, J. L., Langholz, B., Bernstein, L., Burciaga, C., Danley, K., \& Ross, R. K. (1992). Stage and delay in breast cancer diagnosis by race, socio-economic status, age, and year. British Journal of Cancer, 65, 922-926.

Rossi, S., Cinini, C., Di Pietro, C., Lombardi, C., Crucitti, A., Bellatone, R., et al. (1990). Diagnostic delay in breast cancer: Correlation with disease state and prognosis. Tumori, $76,559-562$.

Salovey, P., \& Birnbaum, D. (1989). Influence of mood on health-relevant cognitions. Journal of Personality and Social Psychology, 57, 539-551.

Seligman, M. E. P., \& Csikszentmihalyi, M. (2000). Positive psychology: An introduction. American Psychologist, 55, 5-14.

Strax, P. (1976). Results of mass screening for breast cancer in 50,000 examinations. Cancer, $37,30-35$.

Tallis, F., Eysenck, M., \& Mathews, A. (1991). Elevated evidence requirements and worry. Personality and Individual Differences, 12, 21-27. 
Timko, C. (1987). Seeking medical care for a breast cancer symptom: Determinants of intentions to engage in prompt or delay behavior. Health Psychology, 6, 305-328.

Ward, A. H., Lyubomirsky, S., Sousa, L., \& Nolen-Hoeksema, S. (2003). Can't quite commit: Rumination and uncertainty. Personality and Social Psychology Bulletin, 29, 96-107.

Watson, D., Clark, L. A., \& Tellegen, A. (1988). Development and validation of brief measures of positive and negative affect: The PANAS scales. Journal of Personality and Social Psychology, 54, 1063-1070.

Wilkinson, G., Edgerton, F., Wallace, H., Reese, P., Patterson, J., \& Priore, R. (1979). Delay, staging disease and survival from breast cancer. Journal of Chronic Disease, 32, 365-373. 
Copyright of Journal of Social \& Clinical Psychology is the property of Guilford Publications Inc. and its content may not be copied or emailed to multiple sites or posted to a listserv without the copyright holder's express written permission. However, users may print, download, or email articles for individual use. 